\title{
Investigating the Implementation of Comprehensive Sexuality Education in Selected Public Schools in Samfya District, Zambia
}

\author{
Joseph Mwape $^{1^{*}} \quad$ Ecloss Munsaka ${ }^{2}$ \\ 1.School of Education, Mukuba University, PO box 20382, Off Chingola Road, Kitwe, Zambia \\ 2.School of Education, University of Zambia, Great East Road Campus, PO box 32379, Lusaka, Zambia
}

\section{The research is financed by Mukuba University (Sponsoring information) \\ Abstract}

The controversy on the usefulness of Comprehensive Sexuality Education (CSE) in reducing teen pregnancy in Zambian schools raises concern among educationists and stakeholders. This study sought to investigate the implementation of CSE in selected public schools in Samfya District of Luapula province, Zambia. The study employed a qualitative case study research design involving 27 participants who were purposively selected from three schools in the district. Data were collected using lesson observations, document analysis, semi-structured interviews and Focus Group Discussions). Data analysis was carried out using thematic analysis. The results showed that CSE is implemented in public schools through sensitization of teachers about CSE; integration of CSE into existing subjects; and the use of extra-curricular activities. However, the integration of CSE was not as comprehensive as it should be because teachers tended to focus mainly on topics bordering on human development and sexual and reproductive health, with more emphasis on abstinence, which were already part of the curriculum of the existing subjects. Other important components of CSE such as values, attitudes and skills; culture, society and human rights; sexual behaviour and relationships, were not emphasized upon because teachers, when integrating, did not use the actual CSE framework. In addition, findings suggested that teachers were not adequately trained in CSE delivery as they were just sensitized by others who attended a workshop on CSE. Furthermore, CSE was not fully integrated in extra-curricular activities. There was also no involvement of key stakeholders such as the local community in the implementation of CSE.This led to the conclusion that the implementation of CSE has not been comprehensive because of inadequate training of teachers, failure by teachers to properly integrate CSE using a CSE framework and inadequate extracurricular activities, and less community involvement. Therefore, the study recommends that guidance and counselling teachers should coordinate CSE implementation in schools. Secondly, while CSE themes are covered in other subjects as cross cutting issues, it should also be a standalone subject taught by guidance and counselling teachers. Thirdly, teachers should be adequately trained on how to integrate CSE using a CSE framework.

Keywords: Comprehensive Sexuality Education, Extra-curricular activities, implementation, Integration, sensitization, public schools, Sexuality, Sexual and Reproductive Health, Teenage pregnancy

DOI: $10.7176 / \mathrm{JEP} / 11-32-10$

Publication date: November $30^{\text {th }} 2020$

\section{Background}

Globally, adolescents lack necessary information to help them make proper decisions concerning their sexual lives. United Nations Educational, Scientific and Cultural Organization (UNESCO) (2009, p. 2) postulates, "Few young people receive adequate preparation for their sexual lives; this leaves them potentially vulnerable to coercion, abuse and exploitation, unintended pregnancy and Sexually Transmitted Infections (STIs) including HIV.” This status quo entails that most young people approach adulthood with no clear and correct information about their sexuality.

The issue of adolescents lacking adequate correct information about their sexuality is even more serious in the twenty first century because most adolescents are exposed to illicit material such as pornography and are also exposed to conflicting information about sexual and reproductive issues through the internet and might not have anyone to ask for clarity (UNESCO, 2016). Furthermore, UNESCO (2016) argues that although the internet and social media have been an excellent means of accessing various information, including that on sexual behaviour and reproductive health, most of it is conflicting and distorted.

Lack of information and exposure to illicit materials, such as pornography has partly contributed to the rising numbers of teenage pregnancies among school going girls. This is because despite these adolescents not having adequate correct information on how to deal with their sexuality, they are exposed to sexual materials that leave them vulnerable to illicit sexual intercourse (Onyeonoro, Oshi, Ndimele, Chuku, Onyemuchara, Ezekwere, Oshi, \& Emelumadu, 2011; UNESCO, 2016).

Therefore, CSE is being implemented in public schools to equip adolescents with knowledge and skills to be able to help young people navigate relationships and protect themselves from vices, such as unintended teenage pregnancy. CSE was introduced in Zambian public schools in 2014. It has since been rolled out to all schools, targeting children aged 10-24 in grades 5-12. In order to ensure the successful implementation of CSE, teacher- 
training colleges have included it in their curricula, and it has been integrated into various subjects, such as Home Economics, integrated science, Biology and social studies. This is so in order to ensure that it becomes accessible to all adolescent learners (United Nations International Children's Emergency Fund [UNICEF], 2018; Ministry of Education, Science, Vocational Training and Early Education, 2013).

Ironically, although CSE empowers adolescents by providing information and knowledge about reproductive health and rights, linkages between CSE and reduction in teen pregnancy among school going children in Zambia are limited. An analysis of incidences of teen pregnancies in public schools shows that there is a discrepancy between what is stated in CSE as an expected outcome and what is obtaining on the ground in terms of cases of teen pregnancy among adolescents (Ministry of General Education, 2018). Table 1 below presents cases of teen pregnancy in Zambian public schools from 2013 to 2018.

Table 1: Teenage Pregnancy Cases in Public Schools in Zambia from 2013 to 2018

\begin{tabular}{|c|c|c|c|c|c|c|}
\hline Year & 2013 & 2014 & 2015 & 2016 & 2017 & 2018 \\
\hline $\begin{array}{l}\text { Primary School } \\
\text { Cases }\end{array}$ & 12,500 & 13,275 & 11,989 & 11,765 & 10,684 & 11,453 \\
\hline $\begin{array}{l}\text { Secondary } \\
\text { school cases }\end{array}$ & 2,428 & 3,103 & 3,136 & 3,457 & 2,956 & 3,576 \\
\hline Total cases & 14,928 & 16,378 & 15,125 & 15,222 & 13,640 & 15,029 \\
\hline
\end{tabular}

Source: Ministry of General Education: Educational Statistical Bulletin (2018).

From the table above, it can be noted that the cases of teenage pregnancy are still high despite the implementation of CSE that should help reduce such cases. According to the Ministry of General Education (2018), 13,640 and 15,029 cases of teenage pregnancy were recorded in 2017 and 2018, respectively. This shows that there is no significant decrease from the cases recorded before the introduction of the program in 2013.

Besides, research has provided evidence on the effectiveness of CSE in reducing teenage pregnancy. For instance, Rosen, Murray and Moreland, (2004) and UNESCO (2009) indicate that a properly designed and implemented CSE programme provides young people with knowledge and skills that can be used to reduce some of the risks and underlying vulnerabilities associated with unintended pregnancy and related vices. Moreover, Kirby (2007) argues that a well implemented CSE programme makes students less likely to have sex with multiple partners, delay initial sexual activity, and increases the use of protection when students did have sex.

Kirby, Laris, and Rolleri (2007) submit that CSE programmes emphasize abstinence from all sexual activity as the most reliable method of avoiding and pregnancy and teach adolescents about contraceptives and barrier methods to reduce their risk of becoming pregnant. As such, if well implemented and offered by teachers who have received proper training, they should provide adolescents with developmentally appropriate information regarding a broad range of topics related to sexuality, including puberty, reproductive health, interpersonal relationships, body image, harassment, stigma and discrimination, intimate partner violence, gender norms, gender identity, and sexual orientation. Furthermore, CSE programmes provide opportunities for students to develop communication, decision-making, and other interpersonal skills (UNESCO, 2009).

Further, the International Sexuality and HIV Curriculum Working Group (2011), as experts in the fields of adolescent development, health, and education, recommend Comprehensive Sexuality Education programmes, as part of a comprehensive health education. This is because the programme provides young people with accurate information necessary to protect their sexual health; foster equality, rights, and respect; assist youth in developing a positive view of themselves and their sexuality; and help them acquire skills to communicate effectively, make informed decisions, and stay safe (Haberland, 2015).

In addition, emerging evidence suggests that CSE programmes that pay meaningful attention to issues related to gender and power are more likely than programmes that do not address these topics to demonstrate significant, positive outcomes. For example, Sales, Milhausen, and DiClemente (2006), concluded that broader based content, such as problem solving, capacity building, social skill building, and enhanced gender and ethnic pride, impact greatly on adolescent behaviour. Another review revealed that strikingly, $80 \%$ of curriculum-based programmes that addressed gender or power, as compared with only $17 \%$ of gender-blind programmes, demonstrated significantly lower rates of STIs or pregnancy (Haberland, 2015).

The foregoing literature clearly demonstrates that CSE, if well implemented, provides adolescents with the necessary knowledge, attitudes, and behavioural change towards sexuality, thereby reducing teenage pregnancy. However, the discrepancy between the implementation of CSE in public schools in Zambia and the rise in the cases of teen pregnancy among school going adolescents in Zambia is worrying, thus, the current study interrogated the programme implementation, which is being spear headed by the Ministry of General Education in public schools.

\section{Purpose of the Study}

The purpose of this study was to investigate the implementation of CSE in reducing cases of teenage pregnancy in selected public schools in Samfya district, Zambia. This was not an intervention study, but one that investigated how the implementation of the programme was being done. 


\section{Method}

The method of the study was carried out as detailed in the subsequent section.

\section{Research Design}

The methodology of this study was anchored in the interpretive philosophy, which strives to gain in-depth insight into the lives of participants, to gain an empathetic understanding of why they act in the way that they do. In line with the assumptions espoused in the interpretive philosophy, this study employed a qualitative case study research design in order to have an in depth understanding of the issue under study.

\section{Research participants}

This study had a sample size of 27 participants categorized as follows: Three Guidance and Counselling teachers (one from each of the three schools); three teachers (a teacher of social studies from a primary school, a teacher of Biology from a secondary school, and a teacher of Home Economics from a junior secondary school). Other participants included three parents (one from each school), and eighteen pupils (six from each of the three schools).

\section{Sampling Technique}

The study used purposive sampling to select Samfya district as a study site because it had characteristics of a rural setup where incidences of teen pregnancy are more prevalent. Similarly, three participating schools were purposively selected as they were among schools with the highest cases of teenage pregnancy in the district.

\section{Data Collection Instruments}

Creswell (2009, p. 175) postulates, "qualitative researchers typically gather multiple forms of data, such as interviews, observations and documents rather than relying on a single data source." This study used two data collection instruments namely, semi-structured interviews and the focus group discussions. Semi-structured interviews were conducted with teachers and parents, whereas focus group discussions were conducted with pupils.

\section{Data Collection Procedure}

Firstly, the ethical clearance was sought from the University of Zambia ethical clearance committee. Thereafter, permission was sought from the Provincial Education Officer (PEO), Luapula Province and the District Education Board Secretary (DEBS) in Samfya district.

Data Analysis

According to Merriam and Tisdell (2016, p. 202) "Data analysis is a process of making sense out of the data. And making sense out of data involves consolidating, reducing, and interpreting what people have said and what the researcher has seen and read - it is a process of making meaning." This study followed all necessary steps in thematic data analysis as explained by various qualitative research scholars.

\section{Ethical Consideration}

Issues of ethical consideration were taken into account by explaining the purpose of the study to all participants. Consent was sought from participants and confidentiality was observed. Ethical clearance was obtained from the University of Zambia ethical clearance committee and permission was granted by the Ministry of General Education to conduct the study in the sampled schools.

\section{Results and Discussion}

The study sampled three public schools in Samfya district. In order to ensure confidentiality, schools have been named School 'A', School 'B' and School 'C'. To identify the participants, the initials of their title and a letter representing the school have been used. For example, guidance teachers from School 'A', School 'B' and School ' $C$ ' appear as GTA, GTB and GTC respectively. From School 'A', other participants included Science teacher, a parent and six pupils. They are identified as SCTA, PA, Pp1A, Pp2A, Pp3A, Pp4A, Pp5A and Pp6A respectively. Other participants from School 'B' included Social Studies teacher, a parent and six pupils. They are identified as $\mathrm{SSTB}, \mathrm{PB}, \mathrm{Pp} 1 \mathrm{~B}, \mathrm{Pp} 2 \mathrm{~B}, \mathrm{Pp} 3 \mathrm{~B}, \mathrm{Pp} 4 \mathrm{~B}, \mathrm{Pp} 5 \mathrm{~B}$ and Pp6B respectively. Finally, other participants from School ' $\mathrm{C}$ ' included Home Economics teacher, a parent and six pupils. They are identified as HETC, PC, Pp1C, Pp2C, Pp3C, $\mathrm{Pp} 4 \mathrm{C}, \mathrm{Pp} 5 \mathrm{C}$ and Pp6C respectively. Therefore, a particular participant's identity has been indicated in brackets (...) after its corresponding extract. This format of identifying participants has been used in order to ensure confidentiality and anonymity among participants

The findings revealed that CSE is being implemented in public schools using different modes. Under this, three sub themes emerged. They included: Sensitization of teachers about CSE; integration of CSE into existing subjects; and the use of extra-curricular activities.

\section{Sensitization of teachers about Comprehensive Sexuality Education}

According to the study, some teachers had been trained in CSE through workshops and Continuous Professional Development (CPD). The participants indicated that the head teacher, the guidance teacher and teachers of science, home economics and/or social studies, from each school, were first trained by the District Education Board Secretary's (DEBS) office in collaboration with some organisations at one central place as the trainers to train others. After that, those trained were tasked to train other teachers in their various schools. This is according to the responses from teacher participants as indicated below. For example, one teacher from school 'B' indicated: I, together with the Head teacher, attended a three-day workshop organized by the DEBS office in collaboration 
with some organisations. Everyone is sensitized in the school including parents. (GTB, Interview, June 2019). Another teacher from school A expressed similar sentiments and submitted that:

I have had training in Comprehensive Sexuality Education through the workshop... (SCTA, Interview, June 2019). A guidance teacher from school $\mathrm{C}$ echoed similar sentiments as those expressed above when asked about training of teachers in Comprehensive Sexuality Education:

I have been trained twice in Comprehensive Sexuality Education. All teachers who were around were sensitized through the Continuous Professional Development (CPD). We also intend to sensitise other teachers by the end of next week. (GTC, Interview, June 2019).

From the presentation above, it is clear that some teachers were sensitized in one way or another about CSE delivery. This is in line with UNESCO (2018) submission, which indicates that teachers can be sensitized about CSE delivery through either pre-service training or in-service training using continuous professional development (CPD). However, although some teachers reported being sensitized on CSE delivery, the quality of training leaves much to be desired. This is so because the training used a cascade method, where those who receive the training have to train others, but in the process, quality may be compromised. In fact, UNESCO (2016) suggests that there is need to review the cascade training method.

\section{Integrating Comprehensive Sexuality Education in other subjects}

The study revealed that some teachers were implementing Comprehensive Sexuality Education by integrating it or as a cross cutting issue into the existing subjects and not as a stand-alone subject. Both teachers and pupils from the sampled schools, as evidenced by the excerpts below, confirmed this:

One way is by integrating the CSE topics into the existing subjects such as Science, and Home Economics. (GTA, Interview, 2019).

Another teacher from school ' $\mathrm{C}$ ' indicated:

Comprehensive Sexuality Education is integrated into the existing subjects not as a stand-alone subject. For example, from primary school starting from grade five, it is integrated in social studies... and Religious Studies. (GTC, Interview, June 2019).

Pupils supported the teachers' comments on the integration of Comprehensive Sexuality Education in some subjects. For example, a pupil from school A had this to say:

There are subjects such as science, food and nutrition and social studies where we learn may be about human reproduction, keeping hygiene and issues to do with pregnancies and sexually transmitted infections. (Pp1A, FGD, June 2019).

The above revelation clearly indicates that CSE is not provided as a stand-alone subject, but is either integrated or presented as a cross cutting issue in other subjects that include science, social studies and home economics. This is in agreement with Ministry of Education, Science, Vocational Training and Early Education (2013), which pointed out that in CSE, themes are presented as crosscutting issues and its content integrated in other subjects. Furthermore, UNICEF (2012), recommends that CSE content should be integrated within other existing subjects to avoid overloading teachers and for easy assessment.

Furthermore, the current study revealed that some CSE themes were delivered as crosscutting issues. Thus, one teacher from school 'A' pointed out:

We teach pupils Comprehensive Sexuality Education as a crosscutting issue in other subjects. For example, after teaching reproduction in Integrated Science or Biology, I take time to talk about issues of teenage pregnancies and how they should protect themselves (SCTA, Interview, June 2019).

Another teacher from a different school explained:

We teach pupils Comprehensive Sexuality Education as a crosscutting issue in other subjects. (SSTB, Interview, June 2019).

Pupils also confirmed learning about some CSE related topics. For example, a pupil from school C indicated:

In science, we learn about how a person grows, how a female can become pregnant and also about puberty $(\mathrm{Pp} 3 \mathrm{C}$, FGD, June 2019).

Another pupil from a different school said:

The teacher for Biology teaches us on how a pregnancy takes place and we are also taught on how to protect ourselves from becoming pregnant and also from being infected with HIVIAIDS. We are taught that abstinence is the best but one can also use condoms. (Pp2B, FGD, June 2019)

The above revelation corroborates well with the guidance of Ministry of Education, Science, Vocational Training and Early Education (2013), which indicates that in Zambia, CSE themes feature as crosscutting issues in Zambia Education Curriculum Framework. Furthermore, featuring it as a cross cutting issue provides an opportunity for the key CSE content to be reinforced across the subjects.

Although this is recommended, this scenario leaves the actual delivery of CSE in a particular subject to the individual decision of individual teachers, contrary to the recommendations of UNESCO (2014), which recommends international standards of at least 12 or more lessons (typically lasting approximately 50 minutes) in a year, over several years. Therefore, when the delivery of CSE in other subjects is left to individual teachers' 
initiative, it becomes difficult for the program to be effective.

Zulu, Blystad, Haaland, Michelo, Haukanes and Moland (2019) found a similar scenario in a study conducted in Nyimba, Eastern province of Zambia. This confirms one thing that teachers in various parts of Zambia deliver CSE based on individual choice and not as provided. This implies holding back relevant information from the learners.

Regarding how integration of CSE is done, it became apparent that many teachers were not integrating CSE content from the CSE framework into the existing subjects as required. Teachers were just able to teach the themes as they appear in the various subjects. This was confirmed during the interviews. For example, one teacher of Home Economics indicated:

Mostly, we teach Comprehensive Sexuality Education under health education; that is where most of the topics related to it are. (HETC, Interview, June 2019).

Another teacher from a different school confirmed the above assertion:

Therefore, some of the topics are almost the same as those in these subjects and they are taught in those subjects. (GTA, Interview, 2019).

The practice was uniform in all the three schools sampled as another teacher from school ' $\mathrm{C}$ ' expressed similar sentiments:

Mostly, the topics in CSE are also covered in the existing subjects, so, we just teach such topics in those subjects and emphasize on certain points such as abstaining from sex and alike. (GTC, Interview, June 2019).

The revelation above is inconsistent with the guidance given by Ministry of Education, Science, Vocational Training and Early Education (2013), which demands that the content of CSE should be integrated into existing subjects and that the CSE framework should be used as a guide. Many teachers did not even make mention of using the CSE framework when preparing their lessons. This means that many more important components of CSE were not delivered to the leaners as expected. This scenario is also inconsistent with UNESCO (2016), which indicates that teachers must use the CSE Framework side by side with the syllabi for other subjects to identify areas where CSE can be integrated. This scenario entails CSE is incomprehensively delivered as other major topics that are not included into existing subjects, but are in the CSE are not taught to pupils.

\section{Integrating Comprehensive Sexuality Education into Extra-Curricular Activities}

Apart from integrating Comprehensive Sexuality Education into the existing subjects, the study also revealed that the program was also covered in some extracurricular activities such as clubs, sporting activities and during school assemblies. For example, a teacher from school ' $\mathrm{C}$ ' indicated

We talk about the use contraceptives and sexual hygiene during clubs such as the anti-AIDS club... (GTC, Interview, June 2019).

Yet, another teacher from another school, school A, echoed the same sentiments:

The other way we implement it (CSE) is through clubs such as the Anti-AIDS club where some of such issues mentioned above are discussed. An American volunteer also introduced a girls' club... (GTA, Interview, June 2019).

A teacher from school 'B' explained:

We also talk to them during sporting activities, about four weeks after opening and about two weeks before closing. (GTB, Interview, June 2019).

The above revelation indicates that some activities were done outside the classroom situations. This is in line with the direction as enshrined in the Zambian national policy on education, Educating our Future. The policy directs that some other aspects of children's sexuality should be provided through extra-curricular activities (Government of the Republic of Zambia, 1996). The findings of the current study also indicates that in some areas, some NGOs were collaborating with schools in delivering CSE related activities. This is also, in line with what is reported by The International Planned Parenthood Federation (2016) that some NGOs in South Africa and Nigeria were helping to deliver CSE related activities to adolescents.

Although some extra-curricular activities were reported, their usefulness concerning influencing pupils' sexual behaviour can be doubted. This is because of the absence of many other actors in the implementation of such activities. For example, although the findings suggest that teachers were sensitized about CSE, there was no evidence pointing to the sensitization of parents who are key stakeholders in the provision of CSE. This is inconsistent with the study done by Chandra-Mouli, Plesons, Hadi, Baig and Lang (2018), who recommend sensitizing and engaging key stakeholders such as religious groups, schools, health and education government officials, parents, and adolescents themselves in order to build community consensus and for successful implementation of CSE.

Furthermore, there is no evidence in the findings suggesting the use of peer education, which is also a major component of CSE delivery through extra-curriculum activities. This is inconsistent with what Restless Development (2016) and Doyle (2010) who recommend the importance of peer educators in CSE implementation.

Furthermore, lack of evidence of peer education contradicts the findings by UNESCO (2018), which states that CSE provision in Zambia is also facilitated by peer education and young people's friendly corners. There was 
no evidence of a youth friendly corner at any of the schools sampled. This discrepancy might be due to different sites sampled. UNESCO might have conducted a study in urban areas where youth corners were available.

\section{Conclusion}

The study has revealed that the implementation of CSE is not being comprehensively implemented in some Zambian public schools in Samfya district. Firstly, most teachers were not adequately trained in CSE delivery due to the use of the cascading method. This might have affected the ability of teachers to properly integrate CSE content using the CSE framework into existing subjects. The study has further found that teachers were only delivering CSE to pupils as a crosscutting issue, and only taught the content that is already in the subjects. This scenario meant that the other relevant information captured in CSE framework was not being delivered to pupils. Such information was necessary to empower adolescents in terms of enhancing their skills, values and attitudes to be able to make proper decisions concerning their sexuality. Furthermore, there was lack of peer education and community sensitizations about CSE, which had contributed to weaker extra-curricular activities in schools. This study therefore, recommends a review of CSE implementation in Zambia in order to make it more effective in addressing issues of teen pregnancy. Therefore, guidance and counselling teachers should coordinate CSE implementation in schools. While CSE themes are covered in other subjects as a cross cutting issue, it should also be a standalone subject taught by guidance and counselling teachers. It is also the recommendation of this study that teachers should be adequately trained on how to integrate CSE using the CSE framework.

\section{Reference}

Chandra-Mouli, V., Plesons, M., Hadi, S., Baig, Q., \& Lang, I. (2018). Building Support for Adolescent Sexuality and Reproductive Health Education and Responding to Resistance in Conservative Contexts: Cases from Pakistan. Global Health: Science and Practice; 6(1):128-136.

Cresell, J.W. (2009). Research Design: Qualitative, Quantitative and Mixed Methods Approaches. London: SAGE.

Doyle, A. M. (2010). Older Wiser Safer: evaluation of the long-term impact of an adolescent sexual health intervention programme (MEMAkwa V1/4ana) in Mwanza, Tanzania. PhD thesis, London School of Hygiene \& Tropical Medicine. Accessed from: http://researchonline.lshtm.ac.uk/4646536/

Government of the Republic of Zambia. (1996). Educating our Future: National policy on Education. Lusaka: ZEPH.

Haberland, A. N. (2015). The case for addressing gender and power in sexuality and HIV education: a comprehensive review of evaluation studies. International Perspectives on Sexual and Reproductive Health, 41(1):31-42.

International Sexuality and HIV Curriculum Working Group. (2011). It is All One Curriculum: Guidelines and Activities for a Unified Approach to Sexuality, Gender, HIV, and Human Rights Education. New York, NY: Population Council.

Kirby, D. (2007). Emerging Answers: Research Findings on Programs to Reduce Teen Pregnancy and Sexually Transmitted Diseases. The National Campaign to Prevent Teen and Unplanned Pregnancy. Accessed from :http://www.thenationalcampaign.org/EA2007/EA2007_sum.pdf

Kirby D, Laris BA \& Rolleri LA. (2007). Sex and HIV education programs: their impact on sexual behaviours of young people throughout the world. J Adolesc Health; 40, 206-217.

Leung, H., Shek, D.T.L., Leung, E., \& Shek, E.Y.W. (2019). Development of Contextually relevant Sexuality Education: Lessons from a Comprehensive Review of Adolescent Sexuality Education across Cultures. International Journal of Environment Research and Public Health; 16: 621.

Merriam, S. B., \& Tisdell, J. E. (2016). Qualitative Research: A guide to design and implementation. San Francisco: Jossey-Bass.

Ministry of Education, Science, Vocational Training and Early Education. (2013). Comprehensive Sexuality Education Framework: Grade 5-12. Lusaka: CDC

Ministry of General Education. (2018). Educational Statistical Bulletin. Lusaka: Directorate of Planning and Information.

Onyeonoro, U, Oshi, D. C., Ndimele, E. C., Chuku, N. C., Onyemuchara, I. L., Ezekwere, S.C., Oshi, S. N., \& Emelumadu, O. F. (2011). Sources of sex information and its effects on sexual practices among in-school female adolescents in Osisioma Ngwa LGA, South East Nigeria. Pediatric Adolescent Gynecology 24, $294-$ 299.

Restless Development. (2016). Strengthening Access to Quality Comprehensive Sexuality Education. Kabwe: Author.

Rosen, E. J., Murray, J. N., \& Moreland, S. (2004). Sexuality Education in Schools: The International Experience and Implications for Nigeria. POLICY Working Paper Series No. 12

Sales, J. M., Milhausen, R. R., \& DiClemente, R. J. (2006). A decade in review: building on the experiences of past adolescent STI/HIV interventions to optimise future prevention efforts. Sex Transm Infect; 82,431-436. 
Shadrack, J. (2018). Comprehensive Sexuality Education Impact over Reproductive Health Services: A Case Study of Kinondoni Municipality. A Documentary Review Project Paper.

The International Planned Parenthood Federation (IPPF). (2016). Vision 2020: Everyone's right to know: Delivering comprehensive sexuality education for all young people. London: Author.

United Nations Educational, Scientific and Cultural Organization, United Nations AIDS, United Nations Fund for Population Activities, United Nations International Children's Emergency Fund \& World Health Organisation. (2013). Report on Eastern and Southern Africa (ESA) Ministerial Commitment Meeting and Affirmation Ceremony: why we need a commitment on Comprehensive Sexuality Education and Sexual and Reproductive Health Services for adolescents and young people in Eastern and Southern Africa. Cape Town: Author.

United Nations Educational, Scientific and Cultural Organization, United Nations Fund for Population Activities \& United Nations AIDS. (2016). Fulfilling our promise to young people today: progress review 2013 - 2015 - The Eastern and Southern Africa ministerial committee on Comprehensive Sexuality Education and Sexual and Reproductive Health services for adolescents and young people. New York: Author.

United Nations Educational, Scientific and Cultural Organization. (2009). International Technical Guidance on Sexuality Education: An evidence-informed approach for schools, teachers and health educators. Vol 1: The rationale for sexuality education. Paris: Author.

United Nations Educational, Scientific and Cultural Organization. (2013). Young People today, Time to Act Now: Why Adolescents and Young People Need Comprehensive Sexuality Education and Sexual and Reproductive Health Services in Eastern and Southern Africa. Paris: Author.

United Nations Educational, Scientific and Cultural Organization. (2014). Developing an Education Sector Response to Early and Unintended Pregnancy, Discussion for a Global Consultation. Paris: Author.

United Nations Educational, Scientific and Cultural Organization. (2015). Comprehensive Sexuality Education in Teacher Training in Eastern and Southern Africa. Johannesburg: Author.

United Nations Educational, Scientific and Cultural Organization. (2016). Strengthening Comprehensive Sexuality Education for Young People in School Settings in Zambia: A Review and Documentation of the Scale-up Process. Paris: Author.

United Nations Educational, Scientific and Cultural Organization. (2018). International technical guidance on sexuality education: An evidence-informed approach. Paris: Author.

United Nations International Children's Emergency Fund. (2012). Global evaluation of life skills education programmes: Final report. New York: Author.

United Nations Population Fund. (2014). UNFPA Operational Guidance for Comprehensive Sexuality Education: A Focus on Human Rights and Gender. New York: Author.

United Nations Population Fund. (2015). Girlhood, Not Motherhood: Preventing Adolescent Pregnancy. New York: Author.

Zulu, M. J., Blystad, A., Haaland, E. S. M., Michelo, M., Haukanes, H. \& Moland, M. K. (2019). Why teach sexuality education in school? Teacher discretion in implementing comprehensive sexuality education in rural Zambia. International Journal for Equity in Health, 18, 116 